\title{
Caspase Inhibitor Affords Neuroprotection with Delayed Administration in a Rat Model of Neonatal Hypoxic-Ischemic Brain Injury
}

\author{
Yu Cheng, ${ }^{\star}$ Mohanish Deshmukh, ${ }^{\ddagger}$ Anselm D’Costa, ${ }^{\star}$ Joseph A. Demaro, ${ }^{\star}$ Jeffrey M. Gidday, ${ }^{\S}$ Aarti Shah, ${ }^{\S}$ Yuling Sun, ${ }^{\star}$ \\ Mark F. Jacquin, ${ }^{\star \|}$ Eugene M. Johnson, Jr., ${ }^{\star \neq \|}$ and David M. Holtzman ${ }^{\star \neq \|}$ \\ $*$ Department of Neurology, ${ }^{\ddagger}$ Department of Molecular Biology and Pharmacology, ${ }^{\S}$ Department of Neurosurgery, and the $\|$ Center for the \\ Study of Nervous System Injury, Washington University School of Medicine, St. Louis, Missouri 63110
}

\begin{abstract}
Programmed cell death (apoptosis) is a normal process in the developing nervous system. Recent data suggest that certain features seen in the process of programmed cell death may be favored in the developing versus the adult brain in response to different brain injuries. In a well characterized model of neonatal hypoxia-ischemia, we demonstrate marked but delayed cell death in which there is prominent DNA laddering, TUNEL-labeling, and nuclei with condensed chromatin. Caspase activation, which is required in many cases of apoptotic cell death, also followed a delayed time course after hypoxia-ischemia. Administration of bocaspartyl(OMe)-fluoromethylketone, a pan-caspase inhibitor, was significantly neuroprotective when given by intracerebroventricular injection $3 \mathrm{~h}$ after cerebral hypoxia-ischemia. In addition, systemic injections of boc-aspartyl(OMe)-fluoromethylketone also given in a delayed fashion, resulted in significant neuroprotection. These findings suggest that caspase inhibitors may be able to provide benefit over a prolonged therapeutic window after hypoxic-ischemic events in the developing brain, a major contributor to static encephalopathy and cerebral palsy. (J. Clin. Invest. 1998. 101:19921999.) Key words: caspase • hypoxia • ischemia • cerebral palsy $\bullet$ cell death
\end{abstract}

\section{Introduction}

The anatomic and functional status of the nervous system is sculpted by a normal process during development known as programmed cell death $(1,2)$. The morphology by which cells die during this process is usually apoptotic (3). Cells undergoing apoptosis exhibit condensation of nuclear chromatin, fragmentation of genomic DNA, cytoplasmic shrinkage, and formation of apoptotic bodies $(3,4)$. Biochemical and some morphological features seen during apoptosis are also observed in the brain after adrenalectomy (5) and after some in-

Yu Cheng, Mohanish Deshmukh, and Anselm D'Costa contributed equally to this work.

Address correspondence to David M. Holtzman, Washington University School of Medicine, Department of Neurology, CSNSI, 660 S. Euclid Ave., Box 8111, St. Louis, MO 63110. Phone: 314-3629872; FAX: 314-362-9462; E-mail: holtzman@neuro.wustl.edu

Received for publication 3 November 1997 and accepted in revised form 23 February 1998.

J. Clin. Invest.

(C) The American Society for Clinical Investigation, Inc. 0021-9738/98/05/1992/08 \$2.00

Volume 101, Number 9, May 1998, 1992-1999

http://www.jci.org juries such as trauma (6), and hypoxia-ischemia (H-I) ${ }^{1}$ (7-9). Despite this, most acute insults to the adult brain such as H-I and excitoxicity usually result in necrotic cell death with early cytoplasmic and organelle swelling (10-12).

In the developing central nervous system recent data suggest that cell death can be quite delayed after H-I injury and have some features in common with programmed cell death (13-16). These observations may have important therapeutic consequences in certain disease states. For example, sympathetic neurons from early postnatal animals undergo delayed programmed cell death when deprived of their factor, nerve growth factor (NGF). There is a time-dependent sequence of events after NGF withdrawal-induced apoptosis of sympathetic neurons which suggests that cell death is an active process (17). Genetic and biochemical evidence shows that one of the last intracellular events required for cell death in this and other systems is activation of cysteine proteases termed caspases (for review see references 18-21). Interestingly, bocaspartyl(OMe)-fluoromethylketone (BAF), a cell permeable general caspase inhibitor, can block apoptotic death of all sympathetic neurons when given up to $14 \mathrm{~h}$ after trophic factor withdrawal (22). Similar findings using a different peptide inhibitor have been noted in the NGF-deprived neuronal cell line PC12 (23). These findings suggest that if there is a similar time course of molecular events after brain injuries with prominent delayed cell death, then there may be a prolonged window for therapeutic treatment with caspase inhibitors.

A common cause of brain injury in the perinatal period is H-I. This kind of injury is thought to be the single largest contributor to static encephalopathies in children and can result in mental impairment, seizures, and permanent motor deficits (cerebral palsy) $(24,25)$. The best studied animal model of neonatal H-I injury is based on a variation of the Levine preparation in which postnatal day 7 (P7) rats or mice undergo unilateral carotid ligation followed by exposure to hypoxia which produces severe unilateral brain injury (26-30). This model produces unilateral brain injury in which the neuropathology resembles what is seen in cases of hypoxia and ischemia in term human infants $(24,25,27)$. There is neuronal loss in the cortex, hippocampus, striatum, and thalamus as well as damage to white matter tracts and gliosis. The damage which occurs is diffuse and throughout much of the affected hemisphere; there is not a core infarct or a clear penumbral region. Recent treatment strategies using this model have suggested the potential therapeutic use of oxygen free-radical scavengers, growth factors, excitatory amino acid antagonists, and

1. Abbreviations used in this paper: $\mathrm{BAF}$, boc-aspartyl(OMe)-fluoromethylketone; BTF, boc-threonyl-fluoromethylketone; EM, electron microscopy; H-I, hypoxia-ischemia; ICE, IL- $1 \beta$ converting enzyme; ICV, intracerebroventricular; NGF, nerve growth factor; P, postnatal day; PARP, poly(ADP-ribose)polymerase. 
calcium channel blockers $(30,31)$. In this study we focused on the potential role of a caspase inhibitor. We show that after a unilateral $\mathrm{H}$-I insult in $\mathrm{P} 7$ rats there is evidence of prominent DNA damage in several brain regions, features of which do not begin until $\sim 6 \mathrm{~h}$ after the $\mathrm{H}$-I insult. We also demonstrate that intracerebroventricular (ICV) as well as systemic injections of the caspase inhibitor BAF given either before or up to $3 \mathrm{~h}$ after an $\mathrm{H}-\mathrm{I}$ insult significantly protected $(>50 \%)$ against $\mathrm{H}-\mathrm{I}$ injury. These findings suggest that there may be a long therapeutic window for intervention with caspase inhibitors after H-I insults to the neonatal brain.

\section{Methods}

Animal surgical procedure. A model of H-I based on the Levine procedure was used $(26,30,32)$ with Sprague-Dawley litters (12 pups per litter) at P7. The mean weight of pups in each litter was 12-14 g. Pups were anesthetized with $2.5 \%$ halothane and balance room air, and the left common carotid artery was ligated. The incision was sutured and the pups were returned to their dam for a 2-h recovery and feeding period. The pups were then placed in containers through which humidified $8 \%$ oxygen and balance nitrogen flowed. The containers were submerged in a $36^{\circ} \mathrm{C}$ water bath to maintain normothermia during this period. Pups were kept in the hypoxic chambers for $2.5 \mathrm{~h}$. Thereafter, pups were returned to their dam for $7 \mathrm{~d}$ before killing.

Analysis of DNA fragmentation. Cortical and hippocampal tissue from both lesioned and unlesioned hemispheres was harvested at 0,2 , 6,12 , and $18 \mathrm{~h}$ after completion of an H-I insult (tissue from $n=3$ animals per time point were pooled). The experiment was repeated three times with independent pooled samples. DNA was isolated using the Puregene DNA isolation kit (Centra Systems, Minneapolis, $\mathrm{MN})$ according to the manufacturer's instructions. DNA (10 $\mu \mathrm{g} / \mathrm{lane})$ was electrophoresed on $2 \%$ agarose gel in the presence of $0.3 \mathrm{mg} / \mathrm{ml}$ ethidium bromide and visualized with UV illumination.

TUNEL staining and electron microscopy. At $0,2,6,12$, and $24 \mathrm{~h}$ after an $\mathrm{H}-\mathrm{I}$ insult, rat pups were anesthetized with pentobarbital (150 mg/kg, intraperitoneally) and perfused with ice-cold PBS (four animals per time point for TUNEL and three animals per time point for electron microscopy). Brains were quickly removed and frozen with powdered dry ice for cryostat sectioning. Brain sections $(20 \mu \mathrm{m})$ were then fixed with $10 \%$ buffered formalin, postfixed with acetateethanol solution at $-20^{\circ} \mathrm{C}$, and washed with PBS. An ApopTag in situ apoptosis detection kit (Oncor, Gaithersburg, MD) was used to carry out TUNEL staining as described previously (33). In brief, sections were incubated in equilibration buffer for $10 \mathrm{~min}$ and then terminal deoxynucleotidyl transferase and dUTP-digoxigenin were added to the sections and incubated in a $37^{\circ} \mathrm{C}$ humidified chamber for $1 \mathrm{~h}$. The reaction was then stopped and the slices were washed and incubated with anti-digoxigenin-peroxidase solution, colorized with $\mathrm{DAB} / \mathrm{H}_{2} \mathrm{O}_{2}$, and counterstained with bis-benzamide. For electron microscopy (EM), rat pups were anesthetized with pentobarbital (150 $\mathrm{mg} / \mathrm{kg}$, intraperitoneally) and perfused with $30 \mathrm{ml}$ of PBS followed by $60 \mathrm{ml}$ of $1 \%$ paraformaldehyde, and $2 \%$ glutaraldehyde in PBS (pH 7.4). After continued immersion fixation in the same solution overnight at $4{ }^{\circ} \mathrm{C}$, cortical and hippocampal samples from both lesioned and unlesioned hemispheres were processed for EM as described previously (34).

ICV and systemic injections. BAF and boc-threonyl-fluoromethylketone (BTF) were purchased from Enzyme Systems Products (Livermore, CA). BAF and BTF were kept as a $100 \mathrm{mM}$ stock solution in DMSO. For ICV injections of BAF, BTF, or vehicle, P7 pups received an injection of a 5- $\mu$ l solution containing either vehicle $(1 \mu \mathrm{l}$ DMSO, $4 \mu$ PBS, pH 7.4), BAF (1 $\mu$ l of stock solution, $4 \mu$ PBS), or BTF ( $1 \mu$ l of stock solution, $4 \mu \mathrm{l}$ PBS $)$ as previously described $(30,35$, 36). Injections were performed with a 5- $\mu$ l Hamilton syringe and a 27gauge needle. For each litter undergoing H-I, six animals received the drug (BAF or BTF) and six animals received vehicle. Comparisons were always made between drug- and vehicle-treated littermates. The location of each injection in relation to lambda was $2.0 \mathrm{~mm}$ rostral, $1.5 \mathrm{~mm}$ lateral, and $2.0 \mathrm{~mm}$ deep to the skull surface. For systemic injections, pups underwent unilateral carotid ligation and exposure to hypoxia for $2.5 \mathrm{~h}$. They then received intraperitoneal injections of BAF $(100 \mu \mathrm{l}$ of the $100 \mathrm{mM}$ stock solution) or vehicle $(100 \mu \mathrm{l}$ of DMSO) at 2.5 and $12 \mathrm{~h}$ after removal of the rat pups from the hypoxia chamber. In rats subjected to H-I, mortality rates during surgery, hypoxia, or before killing did not differ between BAF, BTF, and vehicle-treated groups in any of the experiments ( $<5 \%$ per group).

Assessment of brain damage due to $H-I$. 1 wk after $\mathrm{H}-\mathrm{I}$, animals were anesthetized with $150 \mathrm{mg} / \mathrm{kg}$ pentobarbital intraperitoneally and then perfused through the left ventricle with PBS $(\mathrm{pH}$ 7.4) followed by $4 \%$ paraformaldehyde in $0.1 \mathrm{M}$ phosphate buffer $\left(\mathrm{pH} 7.4,4^{\circ} \mathrm{C}\right)$. Brains were then postfixed overnight in the same fixative at $4^{\circ} \mathrm{C}$, cryoprotected in $30 \%(\mathrm{wt} / \mathrm{vol})$ sucrose in $0.1 \mathrm{M}$ phosphate buffer $(\mathrm{pH}$ $7.4,4^{\circ} \mathrm{C}$ ), frozen in powdered dry ice, and stored at $-70^{\circ} \mathrm{C} .50-\mu \mathrm{m}$ serial sections were cut on a freezing sliding microtome. Staining of tissue with Cresyl violet was performed as previously described (36). Damage due to $\mathrm{H}-\mathrm{I}$ was determined by calculating the amount of surviving tissue in coronal sections as described previously (30). Briefly, sections were assessed rostro-caudally from the genu of the corpus callosum to the end of the dorsal hippocampus. The cross-sectional areas of the striatum, cortex, and hippocampus in each of eight equally spaced reference planes were assessed with the NIH image analysis system (version 1.57) linked to a Nikon (Melville, NY) microscope. The sections corresponded approximately to plates 12,15 , $17,20,23,28,31$, and 34 in a rat brain atlas (37). The volume of each brain region was then calculated and the percent volume loss in the lesioned versus the unlesioned hemisphere was determined for each animal as previously described $(30,36)$. For estimation of neuronal density in the CA1 region, neurons in a $5,000-\mu \mathrm{m}^{2}$ region were counted in the right and left hippocampus in three equally spaced sections corresponding to plates 28,31 , and 34 in a rat brain atlas (37). Only neurons (identified by their staining characteristics and size) with nucleoli were counted if they fell within the graticule $(5,000$ $\mu \mathrm{m}^{2}$ ) viewed through a $\times 60$ Nikon oil immersion lens (numerical aperture 1.40). All measurements were done by an investigator blinded to the treatment condition. Nonparametric statistics were used since data were not normally distributed. For statistical analysis, the MannWhitney rank sum test was used to compare groups. The KruskalWallis test was used for comparisons of multiple groups followed by the Mann-Whitney rank sum test including a Bonferroni adjustment for comparison between groups with a $P<0.05$ significance cut off.

Caspase assays and Western blot. Tissue for DEVD-AMC and YVAD-AMC cleavage assays as well as tissue for Western blots was collected from rat pups that were anesthetized with $200 \mathrm{mg} / \mathrm{kg}$ pentobarbital and then perfused transcardially with PBS, $6 \mathrm{ml} / \mathrm{min}(\mathrm{pH}$ 7.4), before removal of the brain and dissection of brain regions. For time course experiments, tissue from the cortex and hippocampus in both lesioned and unlesioned hemispheres was dissected from P7 rat pups at $0,6,12,24$, and $48 \mathrm{~h}$ after $\mathrm{H}-\mathrm{I}$ (tissue from three animals per time point were pooled). For experiments with ICV injections of $\mathrm{BAF}, \mathrm{P} 7 \mathrm{rats}$ underwent left carotid ligation followed by $2.5 \mathrm{~h}$ of exposure to $8 \%$ oxygen. $3 \mathrm{~h}$ later, they received an ICV injection of a $5-\mu \mathrm{l}$ solution containing either vehicle or BAF as described above. $15 \mathrm{~h}$ later, tissue samples were collected from the cortex and hippocampus in both lesioned and unlesioned hemispheres. For caspase assays, tissue samples were then homogenized in $400 \mu \mathrm{l}$ of buffer A $(10 \mathrm{mM}$ Hepes, pH 7.4, $42 \mathrm{mM} \mathrm{KCl}, 5 \mathrm{mM} \mathrm{MgCl}_{2}, 1$ mM DTT, 0.5\% CHAPS, $1 \mathrm{mM}$ PMSF, and $1 \mu \mathrm{g} / \mathrm{ml}$ leupeptin) and centrifuged at 12,000 $\mathrm{g}$ for $10 \mathrm{~min}$ at $4^{\circ} \mathrm{C}$. For detection of poly(ADP-ribose)polymerase (PARP) (EC 2.4.2.30), tissue was lysed in lysis buffer (20 mM Tris, $\mathrm{pH}$ 8.0, $150 \mathrm{mM} \mathrm{NaCl}, 1 \% \mathrm{NP}-40,10 \%$ glycerol, $1 \mathrm{mM}$ PMSF, and 10 $\mu \mathrm{g} / \mathrm{ml}$ aprotinin, and $1 \mu \mathrm{g} / \mathrm{ml}$ leupeptin) and Western blots were performed as previously described (30). The density of the 116-kD band on $\mathrm{x}$-ray film representing uncleaved PARP in tissue samples was 
determined as previously described (38). The PARP antibody was purchased from Enzyme Systems Products. DEVD-AMC and YVAD-AMC cleavage activity was measured from the cell lysate supernatants as described previously (39). Briefly, $25 \mu l$ of the lysate was incubated in a 96-well plate with $75 \mu \mathrm{l}$ of $30 \mu \mathrm{M}$ Ac-DEVDAMC or $10 \mu \mathrm{M}$ Ac-YVAD-AMC (Biomol Research Laboratories Inc., Plymouth Meeting, PA) in buffer B (25 mM Hepes, pH 7.4, 1 mM EDTA, 3 mM DTT, $0.1 \%$ CHAPS, and $10 \%$ sucrose). The incubation was maintained at room temperature for $20 \mathrm{~min}$ in the dark. Fluorescence was measured at an excitation wavelength of $360 \mathrm{~nm}$ and an emission wavelength of $460 \mathrm{~nm}$ in a fluorescent plate reader. The total protein content of the cell lysate was assayed with a NanoOrange protein quantitation kit (Molecular Probes, Eugene, OR) and the data are presented as the absolute fluorescence units per $\mathrm{mg}$ protein per hour.

\section{Results}

A well characterized unilateral brain injury occurs in $\mathrm{P} 7$ rats and mice after unilateral carotid ligation and exposure to $8 \%$ oxygen for $2.5 \mathrm{~h}(26,40)$. The neuropathology in this model resembles what has been observed after H-I injury to the human neonatal brain $(24,27)$. We sought to determine the time course and morphological features of cell death after H-I in this model. P7 rats underwent unilateral (left) carotid ligation followed by exposure to hypoxia ( $8 \%$ oxygen) as previously described $(30,36)$. At different time points after injury, we looked for evidence of DNA damage by assessment of DNA fragmentation as well as by anatomical criteria.

DNA laddering was evident in the hippocampus ipsilateral to carotid ligation but did not appear until $6 \mathrm{~h}$ after H-I (Fig. 1). The laddering, reflective of internucleosomal DNA cleavage, became more prominent at $12 \mathrm{~h}$ and peaked by $18-24 \mathrm{~h}$ af-

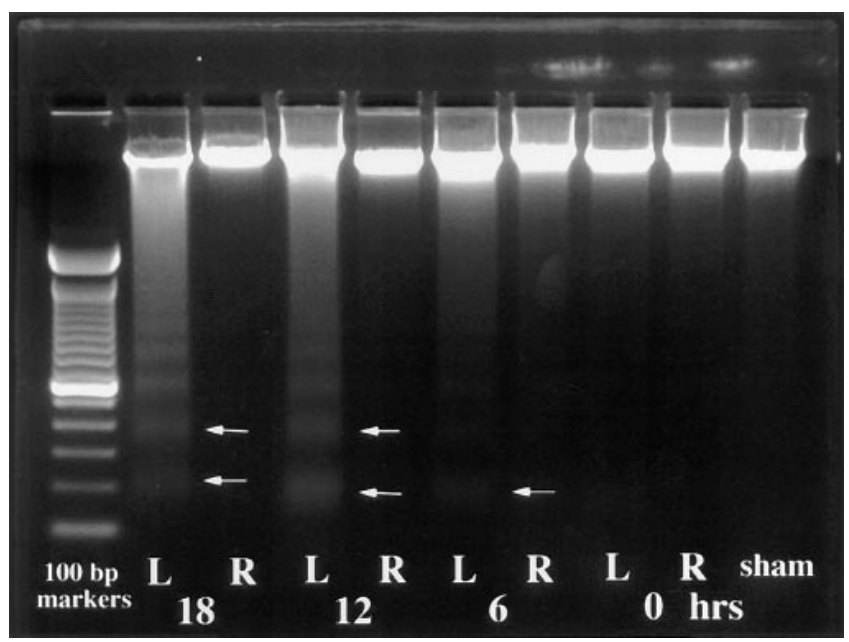

Figure 1. Delayed DNA laddering after H-I in neonatal rats. At different time points after left carotid ligation and exposure to $8 \%$ oxygen for $2.5 \mathrm{~h}$, brain tissue was harvested from three animals per time point and DNA was isolated from the left and right hippocampus. DNA degradation with formation of ladders was first visualized $6 \mathrm{~h}$ after the H-I insult only in the hemisphere ipsilateral to carotid ligation. DNA laddering increased by $12 \mathrm{~h}$ and was slightly greater at $18 \mathrm{~h}$. No DNA laddering was observed in animals which underwent anesthesia but had no carotid ligation or hypoxia (sham). This experiment was repeated with three independent pooled samples per time point with similar results obtained each time.
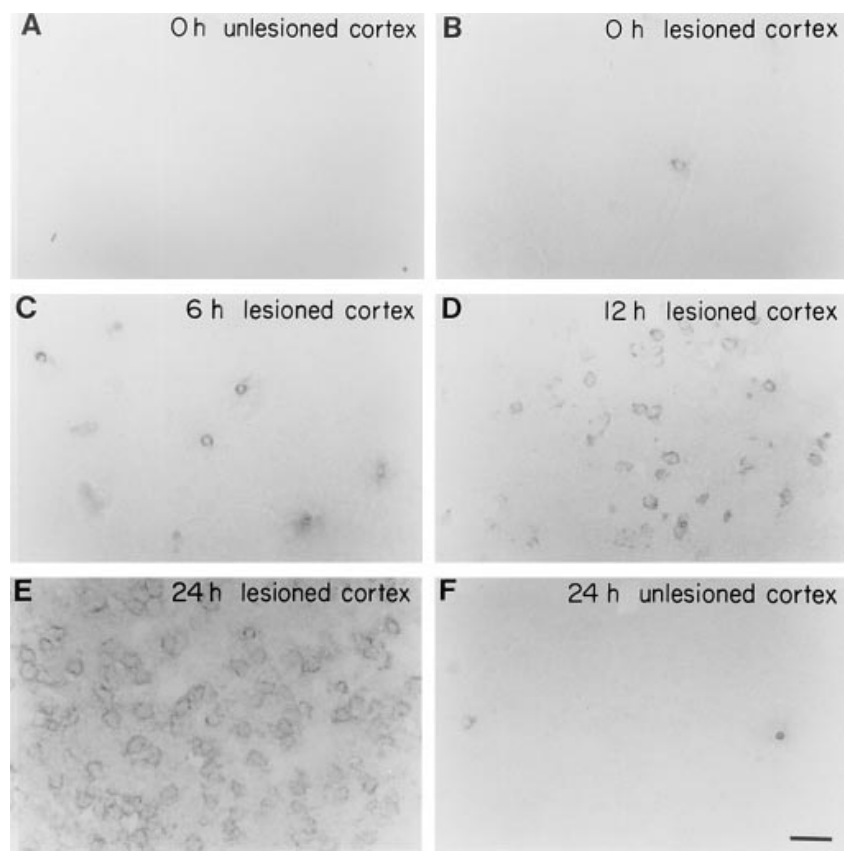

Figure 2. Delayed appearance of TUNEL-labeled cells after neonatal H-I. At different time points after left carotid ligation and exposure to $8 \%$ oxygen for $2.5 \mathrm{~h}$, tissue sections were analyzed for the presence of TUNEL labeling. In the P7 rat brain, immediately $(0 \mathrm{~h})$ after H-I, there were 0-1 TUNEL-positive cells per high power field seen in the cortex both contralateral to the carotid ligation $(A$, unlesioned cortex) as well as ipsilateral to the carotid ligation $(B$, lesioned cortex). Similar findings were noted in the normal P7 brain. An increase in TUNEL-positive cells over baseline was seen in the lesioned cortex beginning $6 \mathrm{~h}$ after $\mathrm{H}-\mathrm{I}(C)$ with increasing numbers of TUNEL-positive cells at $12 \mathrm{~h}(D)$ and the greatest density of TUNEL-positive cells at $24 \mathrm{~h}(E)$. At $24 \mathrm{~h}$ after H-I, there was no increase in the number of TUNEL-positive cells over baseline in the unlesioned cortex $(F)$. The appearance of TUNEL-labeled cells in the hippocampus followed a similar time course (data not shown). Scale bar in $F$ equals $25 \mu \mathrm{m}$.

ter H-I injury. We found no evidence of DNA fragmentation in similar extracts from the lesioned hippocampus at 0 and $2 \mathrm{~h}$ after H-I or in sham-operated animals exposed only to hypoxia. In the hippocampus contralateral to the lesioned hemisphere, there was no visible DNA laddering at any time point examined. A similar time course of DNA fragmentation was seen in DNA extracted from the cerebral cortex of the same animals (data not shown).

TUNEL staining $(33,41)$ has been used extensively to identify cells with nuclear DNA fragmentation. We found a time-dependent increase in the number of TUNEL-positive cells in the hemisphere ipsilateral to carotid ligation (Fig. 2). At 0 and $2 \mathrm{~h}$ after $\mathrm{H}$-I, there were only occasional TUNELpositive cells observed ipsilateral to the carotid ligation; similar numbers of TUNEL-positive cells were observed in the normal P7 brain and in the hemisphere contralateral to carotid ligation (Fig. 2, $A, B$, and $F$ ). $6 \mathrm{~h}$ after H-I, there was a clear increase in TUNEL staining in the hemisphere ipsilateral to carotid ligation. In the cortex, there were approximately three to five cells/high power field $\left(0.043 \mathrm{~mm}^{2}\right)$ noted (Fig. $\left.2 \mathrm{C}\right)$. The TUNEL-positive cells substantially increased in number to 

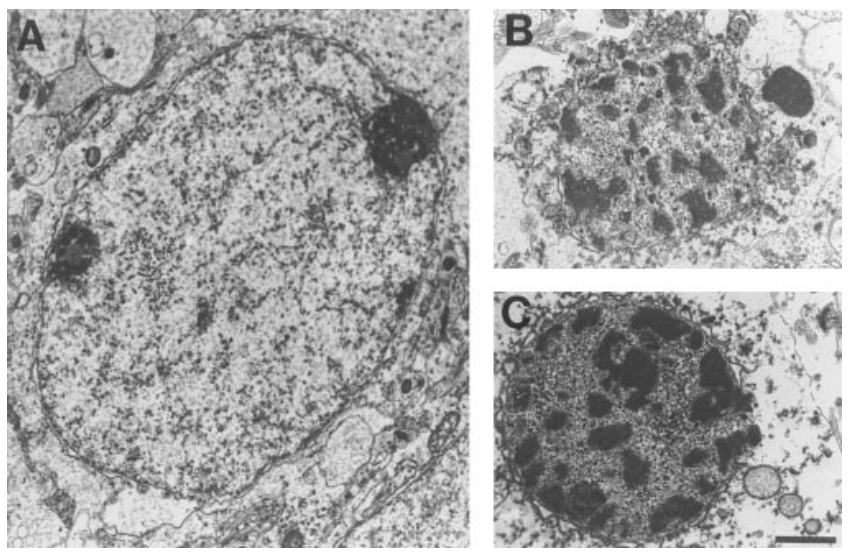

Figure 3. EM analysis of the $\mathrm{P} 7$ neonatal rat brain after $\mathrm{H}-\mathrm{I}$ reveals cells with features of apoptosis. $12 \mathrm{~h}$ after ipsilateral carotid ligation and exposure to $\mathrm{H}-\mathrm{I}$, cell morphology was assessed. In $A$, a normal appearing neuronal nucleus in the pyramidal layer of the hippocampus contralateral to carotid ligation is shown. Examples of shrunken nuclei with condensed chromatin $(B)$ and from the pyramidal layer of the hippocampus ipsilateral to carotid ligation $(C)$ are shown. Scale bar in $C$ equals $2 \mu \mathrm{m}$.

$\sim 20$ cells/high power field at $12 \mathrm{~h}$, and in some fields over 50 cells/high power field were noted $24 \mathrm{~h}$ after H-I (Fig. 2). Although TUNEL-positive cells were sometimes in groups, they were observed throughout different cortical layers. A similar increase in the time course of TUNEL staining was also noted in hippocampus and striatum. We also examined cell morphology by EM at $0,6,12$, and $18 \mathrm{~h}$ after H-I. In the cortex and hippocampus contralateral to carotid ligation, cell and nuclear morphology appeared normal at all time points (Fig. $3 A$ ). By $12 \mathrm{~h}$ after $\mathrm{H}-\mathrm{I}$ ipsilateral to carotid ligation, there was a clear increase in cells which had shrunken nuclei and condensed chromatin in the pyramidal layer of the hippocampus (Fig. 3, $B$ and $C$ ). At $18 \mathrm{~h}$, in addition to these features, several nuclei had apoptotic bodies (data not shown). Similar findings were seen in the cortex. These findings suggest that changes consistent with apoptosis appear to occur after neonatal H-I injury.

Accumulating evidence indicates that activation of IL-1 $\beta$ converting enzyme (ICE)-like proteases (caspases) is critical for many forms of apoptotic cell death (for reviews see references 19 and 21). We examined whether caspase-like activity was increased after neonatal H-I. Brain extracts from P7 cortex both ipsilateral and contralateral to the lesioned hemisphere were incubated with the tetrapeptide substrates Ac-DEVDAMC or Ac-YVAD-AMC. DEVD-AMC is a preferred substrate for caspase-3-like (2,3, and 7) and YVAD is a preferred substrate for caspase-1-like enzymes (1, 4, and 5). Enzyme activity was assayed spectrophotometrically by measuring the extent of cleavage of the peptide substrates by the extracts. In the hippocampus ipsilateral to the carotid ligation, caspase-3like activity was notably increased $12 \mathrm{~h}$ after H-I, peaked by $\sim 24-36 \mathrm{~h}$, and then dropped back to almost basal levels by $48 \mathrm{~h}$ (Fig. 4). Contralateral to carotid ligation, no significant increase in caspase-3-like activity was observed up to $48 \mathrm{~h}$ after $\mathrm{H}-\mathrm{I}$ insult. In contrast to the increase in caspase-3-like activity after H-I, there was no clear increase in YVAD-AMC cleavage (caspase-1-like activity) (data not shown). Thus, by both anatomical (TUNEL and EM) and biochemical criteria (DNA laddering and caspase activation), cell injury in this model is delayed with onset at $\sim 6 \mathrm{~h}$ and becoming prominent by $12-24 \mathrm{~h}$ after H-I.

BAF is a general caspase inhibitor which is an effective inhibitor of NGF deprivation-induced sympathetic neuronal death in vitro (22). Caspases are activated late in the pathway of sympathetic neuronal death, and BAF treatment blocks programmed cell death in NGF-deprived sympathetic neurons even when given in a delayed fashion up to $14 \mathrm{~h}$ after NGF deprivation in vitro (22). Since our data indicated that after neonatal H-I there is a substantial delay in neuronal injury at least part of which resembles programmed cell death, we examined whether the caspase inhibitor BAF could provide neuroprotection when administered in this injury model. One dose of BAF (100 nmol) or vehicle was administered ICV $3 \mathrm{~h}$ after completion of carotid ligation and of exposure to $8 \%$ oxygen. Brains were then analyzed 1 wk later to quantify the extent of brain injury as previously described (30). In vehicle-treated animals, brain volume loss in the lesioned hemisphere $7 \mathrm{~d}$ after H-I treatment revealed a $28.8 \%$ volume loss in striatum, $45.2 \%$ in hippocampus, and $35.4 \%$ in cortex as compared to the control, contralateral hemisphere (Fig. 5). A single ICV dose of BAF given $3 \mathrm{~h}$ after completion of the $\mathrm{H}-\mathrm{I}$ insult significantly reduced brain volume loss by $>50 \%$ in all three brain regions (Fig. 5). In a separate group of animals, administration of BAF immediately before carotid ligation and subsequent hypoxia did not afford additional neuroprotection (Fig. 5). BAF treatment did not affect the core temperature of animals at 1 and $2 \mathrm{~h}$ after administration suggesting that the effect of BAF was not due to hypothermia (Table I). To determine the specificity of the marked protective effects seen with BAF, we also determined whether a peptide similar in structure to BAF, $\mathrm{BTF}$, which does not inhibit caspase activity and also has a flu-

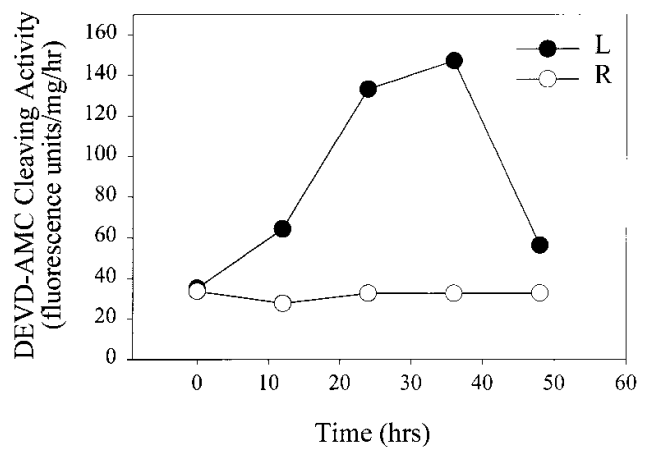

Figure 4. DEVD-cleaving activity in the $\mathrm{P} 7$ rat brain after H-I. At different time points after left carotid ligation and exposure to $8 \%$ oxygen for $2.5 \mathrm{~h}$, tissue was harvested from the left and right hippocampus. The cleavage of Ac-DEVD-AMC, which reflects caspase-3like activity, was measured in tissue extracts. The amount of DEVDcleaving activity in normal P7 hippocampus was similar to that found contralateral to carotid ligation at all time points; however, by $12 \mathrm{~h}$ there was increased activity in the hippocampus ipsilateral to carotid ligation. This activity peaked between 24 and $36 \mathrm{~h}$ before returning to near baseline levels at $48 \mathrm{~h}$. Each data point represents the activity measured in the tissue pooled from three littermates per time point. The data are represented as a percentage of DEVD-AMC cleaving activity at the $0 \mathrm{~h}$ time point. The data shown are representative of three other experiments performed on separate tissue samples. 
A.
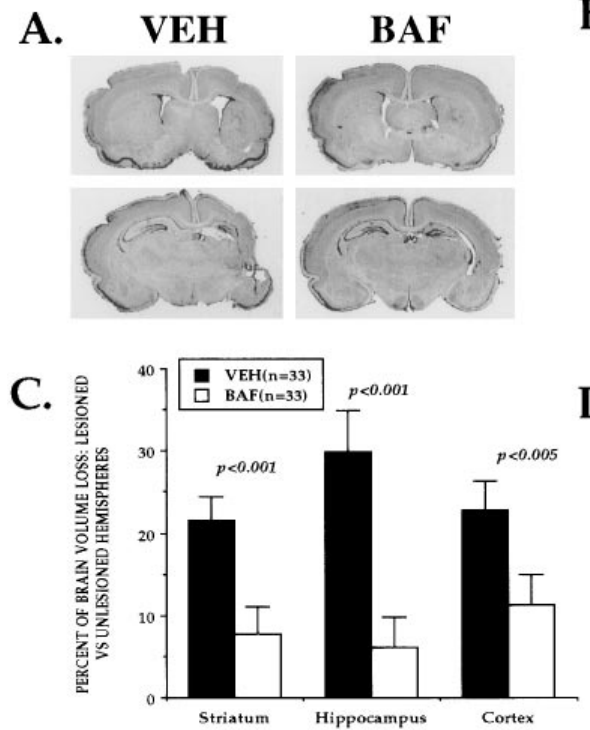

D.

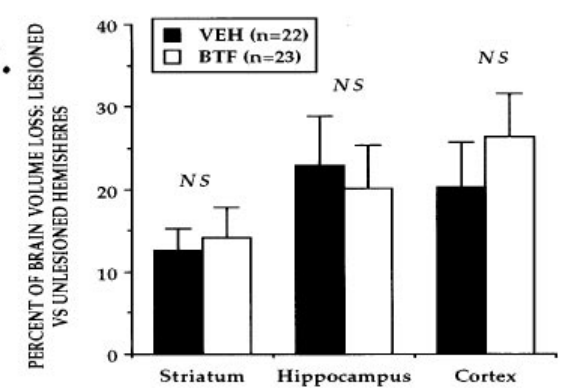

E.

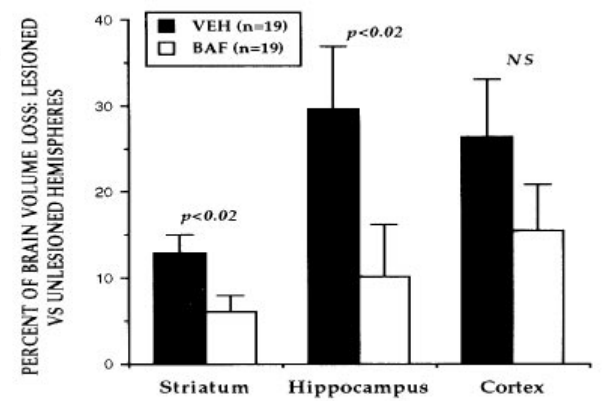

\section{B.}

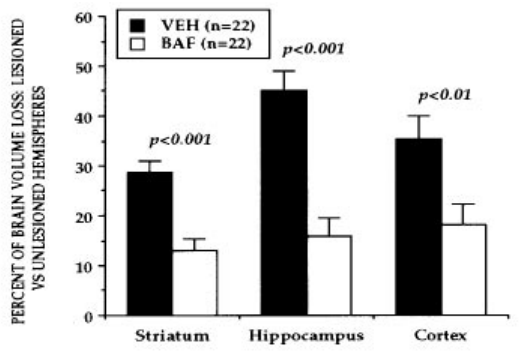

Figure 5. BAF significantly protects the neonatal rat brain from $\mathrm{H}-\mathrm{I}$. An example of unilateral hemispheric tissue loss $(A)$ is shown in a P14 animal treated $1 \mathrm{wk}$ before with vehicle (VEH) versus an animal treated with BAF $3 \mathrm{~h}$ after unilateral carotid ligation and exposure to $8 \%$ oxygen at P7. A single ICV injection of BAF (100 $\mathrm{nmol}$ ) significantly protected the $\mathrm{P} 7 \mathrm{rat}$ brain when given just before $(B)$ or $3 \mathrm{~h}$ after $(C) \mathrm{H}-\mathrm{I}$. BAF protected against $>50 \%$ of tissue loss in cortex, hippocampus, and striatum in both instances. BTF, a control peptide, did not protect the neonatal brain from an H-I insult $(D)$. Delayed administration of systemic BAF also resulted in significant neuroprotection in both the hippocampus and striatum $(E)$. In $A-E$, brains were analyzed at P14, $7 \mathrm{~d}$ after an H-I insult at P7. oromethylketone moiety, had any protective effects in this model. We found that when $100 \mathrm{nmol}$ of BTF was administered ICV $3 \mathrm{~h}$ after an H-I insult, there was no significant protection as compared to vehicle-treated control littermates. Because BAF is a lipophilic, cell permeable molecule, we also asked whether systemic administration would be protective. $\mathrm{P} 7$ rats received intraperitoneal injections of $\mathrm{BAF}$ or vehicle both 2.5 and $12 \mathrm{~h}$ after $\mathrm{H}$-I. In BAF-treated animals, there was $66 \%$ less tissue loss in the hippocampus, $53 \%$ less in the striatum, and $33 \%$ less in the cortex. These changes were statistically significant in both the hippocampus and striatum. To determine if the protection by systemic BAF against brain volume loss correlates with neuronal protection, we determined neuronal density in the CA1 region of the hippocampus in the same animals. In vehicle-treated animals, CA1 neuronal

Table I. Core Temperature in P7 Rats Given ICV BAF $3 \mathrm{~h}$ after H-I Insult

\begin{tabular}{lccc}
\hline & Basal temperature & 1 h after injection & 2 h after injection \\
\hline \multicolumn{1}{c}{${ }^{\circ} \mathrm{C}$} & ${ }^{\circ} \mathrm{C}$ & ${ }^{\circ} \mathrm{C}$ \\
& & & $37.1 \pm 0.26$ \\
BAF & $37.3 \pm 0.26(n=19)$ & $37.4 \pm 0.27$ \\
Vehicle & $37.4 \pm 0.19(n=19)$ & $37.1 \pm 0.28$ & $37.2 \pm 0.24$ \\
& & & \\
\hline
\end{tabular}

Mean \pm SEM density decreased by $50 \%$ in the lesioned versus the unlesioned hemisphere. In contrast, CA1 neuronal density decreased by only $20 \%$ in the lesioned versus the unlesioned hemisphere in BAF-treated animals (Fig. 6). Systemic BAF did not result in changes in core temperature 1 and $2 \mathrm{~h}$ after injection (data not shown).

To confirm that the neuroprotection afforded by BAF administration was correlated with its ability to inhibit caspase activity, we examined whether BAF was able to inhibit caspase activity as well as PARP cleavage in vivo. P7 rats were subjected to an $\mathrm{H}-\mathrm{I}$ insult. $3 \mathrm{~h}$ after $\mathrm{H}$-I, they received a single ICV injection of either BAF or vehicle. $18 \mathrm{~h}$ after H-I, brain tissue was removed and assayed for caspase-3-like activity. In vehicle-treated animals, there was a 5-fold increase in caspase3 -like activity in the hippocampus and a 2.5 -fold increase in activity in the cortex of ipsilateral to carotid ligation. Relative to vehicle-treated samples, BAF treatment resulted in a significant reduction in caspase-3-like activity in both hippocampus and cortex ipsilateral to carotid ligation (Fig. 7). In contrast to the increase in caspase-3-like activity $18 \mathrm{~h}$ after $\mathrm{H}-\mathrm{I}$, there was no $\mathrm{H}-\mathrm{I}-$-induced increase in caspase-1-like activity in the same tissue samples (Fig. 7). BAF treatment did not result in a further decrease in baseline caspase-1-like activity observed in vehicle-treated samples. Since it has been shown that BAF can directly inhibit caspase-1 activity (22), this suggests that each tissue has some baseline cleaving activity when used in this assay which is not secondary to endogenous caspase activation. 


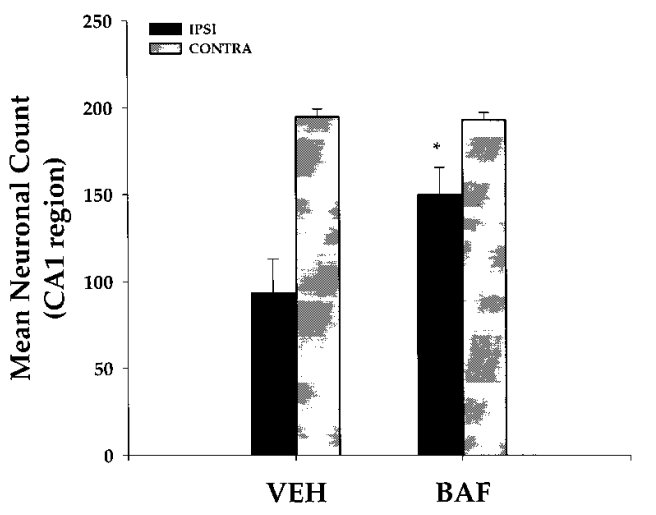

Figure 6. Mean neuronal counts in the CA1 region 1 wk after unilateral carotid ligation, exposure to hypoxia at $\mathrm{P} 7$ followed by treatment with systemic BAF or vehicle (VEH). Neurons in the left and right CA1 region of the hippocampus were counted in a $5,000-\mu \mathrm{m}^{2}$ region in three sections (total, $15,000 \mu \mathrm{m}^{2}$ ) with a calibrated microscopic eyepiece. In rats treated with systemic BAF, neuronal density was significantly greater in the lesioned hippocampus ipsilateral (IPSI) to carotid ligation than in the lesioned vehicle-treated hippocampus ipsilateral to carotid ligation $\left({ }^{*} P<0.01\right) 1 \mathrm{wk}$ after $\mathrm{H}-\mathrm{I}$. There was no significant difference in the mean CA1 neuronal density between vehicle- and BAF-treated animals in the unlesioned hippocampus contralateral $(C O N T R A)$ to carotid ligation.

To address whether residual unreacted BAF remaining in the tissue could account for inhibition of caspase-3-like activity in our assay after tissue lysis, we performed an experiment in which we mixed vehicle-treated ischemic hippocampal lysate (18 h after H-I) which had high DEVD-AMC cleaving activity with hippocampal lysate from tissue injected with ICV BAF $15 \mathrm{~h}$ before. There was no further inhibition of DEVD-AMC cleavage activity after mixing the samples (data not shown). Finally, we also assessed whether ICV injection of BAF inhibited the cleavage of PARP, a substrate for caspase-3. As detected by Western blot, there was significantly less cleavage of PARP in hippocampal samples from BAF as compared to vehicletreated animals ipsilateral to carotid ligation (percent decrease in full length PARP, ipsilateral versus contralateral hippocampus, mean \pm SEM: BAF, $-10.8 \pm 9 \%, n=10$ vs. Vehicle, $-52.9 \pm 5.3 \%, n=10 ; P<0.01)$. Taken together, these results suggest that the mechanism for the in vivo neuroprotection by BAF is through inhibition of caspase activation and subsequent steps leading to cell death.

\section{Discussion}

There are two main findings in this study. First, we have shown that in a well characterized animal model of neonatal H-I, there is evidence of delayed cell injury with DNA damage 6-24 h after the insult as detected with both biochemical and anatomical methods. Second and most importantly, a cell permeable pan-caspase inhibitor, BAF, significantly attenuated tissue injury due to H-I even when administered $3 \mathrm{~h}$ after H-I. The fact that both delayed and systemic injections were protective has important clinical implications. These findings suggest that molecules which can interrupt terminal events in the cell death pathway may be very useful in the treatment of neo-
$\mathbf{A}$

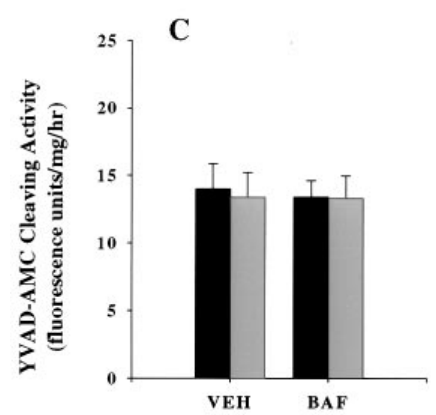

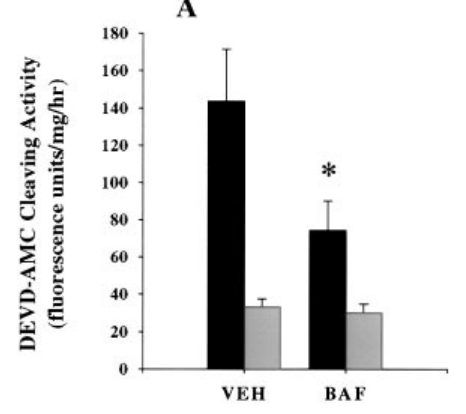

B
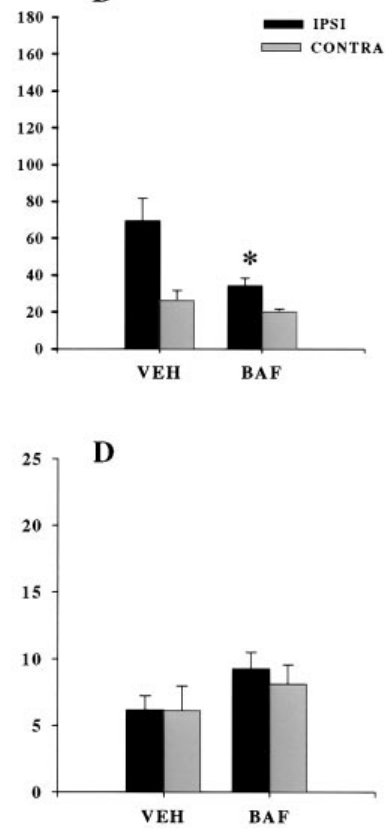

$\mathbf{E}$

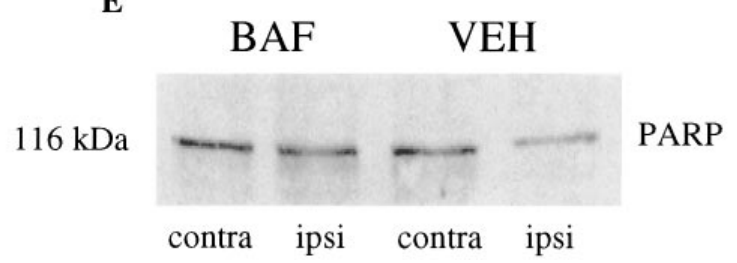

Figure 7. DEVD- and YVAD-cleaving activity as well as PARP cleavage in the $\mathrm{P} 7 \mathrm{rat}$ brain $18 \mathrm{~h}$ after $\mathrm{H}-\mathrm{I}$ in animals is affected by treatment with ICV BAF. $3 \mathrm{~h}$ after unilateral carotid ligation and exposure to hypoxia, $\mathrm{P} 7$ rats received ICV injections of either BAF or vehicle. $15 \mathrm{~h}$ later, tissue was harvested and the extent of cleavage of Ac-DEVD-AMC and YVAD-AMC as well as the level of PARP was determined. DEVD-AMC cleaving activity was elevated in both the hippocampus and cortex ipsilateral (IPSI) to carotid ligation in vehicle-treated animals $(A$ and $B$ ). There was significantly less DEVDAMC cleaving activity in the hippocampus and cortex ipsilateral to carotid ligation when comparing BAF- versus vehicle-treated animals $\left({ }^{*} P<0.05\right)(A$ and $B)$. DEVD-AMC cleaving activity was similar in both treatment groups in the hippocampus and cortex contralateral $(C O N T R A)$ to carotid ligation. YVAD-cleaving activity was not significantly elevated at $18 \mathrm{~h}$ after $\mathrm{H}-\mathrm{I}$ in the hippocampus or cortex in BAF- or vehicle-treated animals $(C$ and $D)$. The level of full-length PARP (116 kD) was also determined by Western blotting with an anti-PARP antibody in hippocampal tissue from animals which received an H-I insult and were treated with ICV BAF or vehicle. BAF-treated samples had a significantly greater amount of fulllength 116-kD PARP in hippocampal lysates ipsilateral versus contralateral to carotid ligation as compared to vehicle-treated samples (see Results). An example from a representative Western blot is shown in $E$. 
natal $\mathrm{H}-\mathrm{I}$ brain injury and possibly other acute injuries to the neonatal brain.

In neonatal H-I models, there is previous evidence that cerebral ischemia leads to delayed cell death with DNA damage (13-15). For example, $12 \mathrm{~h}$ after bilateral carotid ligation and exposure to 15 min of hypoxia in P8 rats, TUNEL labeling and karyorrhectic cells can be identified (13). Extensive DNA laddering was observed by others (14) at $18 \mathrm{~h}$ after $\mathrm{H}-\mathrm{I}$ in the neonatal model we used; however, only this one time point was examined. We used both biochemical and anatomical criteria to look for the occurrence and time course of DNA damage and caspase activation in this model. Both TUNEL labeling and DNA laddering revealed evidence for DNA damage beginning at $6 \mathrm{~h}$ after H-I. These methods are sensitive but not always specific for apoptosis. For example, it has been shown in cultured cells that while most cells with DNA laddering are dying via apoptosis, there are exceptions in which DNA laddering is present in the setting of necrosis (42). EM analysis, however, also appears to confirm that at least some of the cell death occurring in this model is consistent with apoptosis. The potential importance of our findings of DNA damage along with delayed caspase activation is that cell death with these features can be under active cell control. For example, functional inhibition of ced-3 in Caenorhabditis elegans (43) or the mammalian homologues of ced-3 (caspases) can prevent cell death in diverse cell types, including neurons $(18,19,44)$. Whether caspase inhibitors would be protective after acute nervous system injury is just beginning to be studied. Recent findings using IL-1 $\beta$-like protease inhibitors including $z$-VADDCB in adult rats (45) and z-VAD.FMK in adult mice (46) showed decreases in ischemic damage after ICV administration in the setting of middle cerebral artery occlusion. In one study, z-VAD-DCB was given just before ischemia (45), and in the other, z-VAD.FMK was protective when administered at the end of arterial occlusion but not when treatment was delayed by $1 \mathrm{~h}$. Whether delayed treatment was not as effective as BAF in our model may be due to differences in the drugs, the models, or developmental age at time of injury.

To our knowledge, this is the first demonstration that both delayed and systemic administration of a caspase inhibitor can be neuroprotective in an injury model. In neonatal H-I, BAF may be affording neuroprotection in at least two ways. First, it may inhibit cell death by inhibiting cleavage of substrates in cells with activated caspases. It is also possible that reduction in brain injury from inflammation and edema occurs secondary to inhibition of a specific caspase such as ICE (18), with subsequent decreases in the formation of IL-1 $\beta$. A combination of these two possibilities may also occur. It is interesting to note that IL-1 $\beta$ expression is increased after neonatal $\mathrm{H}-\mathrm{I}$ injury and that adenoviral-mediated overexpression of IL-1 $\beta$ receptor antagonist is neuroprotective against neonatal $\mathrm{H}-\mathrm{I}$ injury $(47,48)$. Using the DEVD-AMC and YVAD-AMC cleavage assays, our data suggest that there is not a significant increase in caspase-1-like activity after neonatal H-I. It is conceivable, however, that if caspase-1-like activity was selectively increased only in inflammatory and not neural cells after neonatal H-I, our assay would not detect this change. The fact that we have seen as much neuroprotection against neonatal $\mathrm{H}-\mathrm{I}$ injury when BAF is administered before as well as $3 \mathrm{~h}$ after injury may be due to several factors including the prominent and delayed injury with features of apoptosis which occurs after H-I injury in the neonatal brain.
While BAF can inhibit NGF deprivation-induced death of sympathetic neurons in vitro, it does not inhibit many of the more proximal events after NGF removal that lead the cell to the point where it was ready to undergo execution (22). It is unlikely that such cells, while saved by BAF, maintain normal function; our finding of abnormal electrophysiology in these cells supports this assertion (Werth, J.L., J. Cocabo, M. Deshmukh, E.M. Johnson, Jr., and S.M. Rothman, unpublished data). Despite this, even after long periods of NGF deprivation, these BAF-saved cells can return to a normal trophic state upon reexposure to NGF (22). In neonatal H-I, while there is severe energy depletion and a variety of other events (25) which are likely to lead to apoptotic cell death, delayed administration of BAF is still protective suggesting that these biochemical and cellular abnormalities are not permanent. Thus, after acute injury to the developing brain, antiapoptotic therapy may buy enough time for cells until a more normal trophic environment is reestablished to maintain and restore cellular function (21). Experiments to further test this possibility as well as how late caspase inhibitors can be given and still be protective are underway.

\section{Acknowledgments}

The authors wish to thank Dr. D. Ferriero for helpful comments and S. Patel, M. Parsadanian, and K. Salimi for their technical assistance.

This work was supported by National Institutes of Health grants NS-35902 (David M. Holtzman), DE-07734 (Mark F. Jacquin), AG12947 (Eugene M. Johnson), a PVA Spinal Cord Research Foundation grant (Mohanish Deshmukh), and a Paul Beeson Physician Faculty Scholar Award from the American Federation for Aging Research (David M. Holtzman).

\section{References}

1. Oppenheim, R.W. 1991. Cell death during the development of the nervous system. Annu. Rev. Neurosci. 14:453-501.

2. Raff, M.C., B.A. Barres, J.F. Burne, H.S. Coles, Y. Ishizaki, and M.D. Jacobson. 1993. Programmed cell death and the control of cell survival: lessons from the nervous system. Science. 262:695-700.

3. Wyllie, A.H., J.F. Kerr, and A.R. Currie. 1980. Cell death: the significance of apoptosis. Int. Rev. Cytol. 68:251-306.

4. Schwartzman, R.A., and J.A. Cidlowski. 1993. Apoptosis: the biochemistry and molecular biology of programmed cell death. Endocr. Rev. 14:133-151.

5. Sloviter, R.S., E. Dean, and S. Neubort. 1993. Electron microscopic analysis of adrenalectomy-induced hippocampal granule cell degeneration in the rat: apoptosis in the adult central nervous system. J. Comp. Neurol. 33:337-351.

6. Rink, A., K.M. Fung, J.Q. Trojanowski, V.M. Lee, E. Neugebauer, and T.K. McIntosh. 1995. Evidence of apoptotic cell death after experimental traumatic brain injury in the rat. Am. J. Pathol. 147:1575-1583.

7. Goto, K., A. Ishige, K. Sekiguchi, S. Iizuka, A. Sugimoto, M. Yuzurihara, M. Aburada, E. Hosoya, and K. Kogure. 1990. Effects of cycloheximide on delayed neuronal death in rat hippocampus. Brain Res. 534:299-302.

8. Tominaga, T., S. Kure, K. Narisawa, and T. Yoshimoto. 1993. Endonuclease activation following focal cerebral ischemic injury in the rat brain. Brain Res. 608:21-26.

9. Nitatori, T., N. Sato, S. Waguri, Y. Karasawa, H. Araki, K. Shibanai, E. Kominami, and Y. Uchiyama. 1995. Delayed neuronal death in the CA1 pyramidal layer of the gerbil hippocampus following transient ischemia is apoptosis. J. Neurosci. 15:1001-1011.

10. Brown, A.W., and J.B. Brierley. 1972. Anoxic-ischeamic cell change in rat brain: light microscopic and fine-structural observations. J. Neurol. Sci. 16: 59-84.

11. Deshpande, J., K. Bergstedt, T. Linden, H. Kalimo, and T. Wieloch. 1992. Ultrastructural changes in the hippocampal CA1 region following transient cerebral ischemia: evidence against programmed cell death. Exp. Brain Res. 88:91-105.

12. Rothman, S.M., and J.W. Olney. 1986. Glutamate and the pathophysiology of hypoxic-ischemic brain damage. Ann. Neurol. 19:105-111.

13. Ferrer, I., A. Tortosa, A. Macaya, A. Sierra, D. Moreno, F. Munell, R. Bianco, and W. Squier. 1994. Evidence of nuclear DNA fragmentation follow- 
ing hypoxia-ischemia in the infant rat brain, and transient forebrain ischemia in the adult gerbil. Brain Path. 4:115-122.

14. Hill, I.E., J.P. MacManus, I. Rasquinha, and U.I. Tuor. 1995. DNA fragmentation indicative of apoptosis following unilateral cerebral hypoxia-ischemia in the neonatal rat. Brain Res. 676:398-403.

15. Sidhu, S., U.I. Tuor, and M.R. Del Bigio. 1997. Nuclear condensation and fragmentation following cerebral hypoxia-ischemia occurs more frequently in immature than older rats. Neurosci. Lett. 223:129-132.

16. Portera-Cailliau, C., D.L. Price, and L.J. Martin. 1997. Excitotoxic neuronal death in the immature brain is an apoptosis-necrosis morphological continuum. J. Comp. Neurol. 378:70-87.

17. Deckwerth, T.L., and E.M. Johnson, Jr. 1993. Temporal analysis of events associated with programmed cell death (apoptosis) of sympathetic neurons deprived of nerve growth factor. J. Cell Biol. 123:1207-1222.

18. Kumar, S., and M.F. Lavin. 1996. The ICE family of cysteine proteases as effectors of cell death. Cell Death Differ. 3:255-267.

19. Schwartz, L.M., and C.E. Milligan. 1996. Cold thoughts of death: the role of ICE proteases in neuronal death. Trends Neurosci. 19:555-562.

20. Deshmukh, M., and E.M.J. Johnson. 1997. Programmed cell death in neurons: focus on the pathway of nerve growth factor deprivation-induced death of sympathetic neurons. Mol. Pharmacol. 51:897-906.

21. Holtzman, D.M., and M. Deshmukh. 1997. Caspases: a treatment target for neurodegenerative diseases? Nature Med. 3:954-955.

22. Deshmukh, M., J. Vasilakos, T.L. Deckwerth, P.A. Lampe, B.D. Shivers, and E.M. Johnson, Jr. 1996. Genetic and metabolic status of NGF-deprived sympathetic neurons saved by an inhibitor of ICE family proteases. J. Cell Biol. 135:1341-1345.

23. Troy, C.M., L. Stefanis, A. Prochiantz, L.A. Greene, and M.L. Shelanski. 1996. The contrasting roles of ICE family proteases and interleukin-1 $\beta$ in apoptosis induced by trophic factor withdrawal and by copper/zinc superoxide dismutase down-regulation. Proc. Natl. Acad. Sci. USA. 93:5635-5640.

24. Volpe, J.J. 1993. Neurology of the Newborn. W.B. Saunders, Philadelphia, PA. 876 pp.

25. Vanucci, R.C. 1990. Experimental biology of cerebral hypoxia-ischemia: relation to perinatal brain damage. Pediatr. Res. 27:317-326.

26. Rice, J.E., R.C. Vannucci, and J.B. Brierley. 1981. The influence of immaturity on hypoxic-ischemic brain damage in the rat. Ann. Neurol. 9:131-141.

27. Johnston, M.V. 1983. Neurotransmitter alterations in a model of perinatal hypoxic-ischemic brain injury. Ann. Neurol. 13:511-518.

28. Silverstein, F., and M.V. Johnston. 1984. Effects of hypoxia-ischemia on monoamine metabolism in the immature brain. Ann. Neurol. 15:342-347.

29. Ferriero, D.M., L.J. Arcavi, S.M. Sagar, T.K. McIntosh, and R.P. Simon. 1988. Selective sparing of NADPH-diaphorase neurons in neonatal hypoxiaischemia. Ann. Neurol. 24:670-676.

30. Cheng, Y., J.M. Gidday, Q. Yan, A.R. Shah, and D.M. Holtzman. 1997. Marked age-dependent neuroprotection by BDNF against neonatal hypoxicischemic brain injury. Ann. Neurol. 41:521-529.

31. Palmer, C., and R.C. Vanucci. 1993. Potential new therapies for perinatal cerebral hypoxia-ischemia. Clin. Perinatol. 20:411-432.

32. Gidday, J.M., J.C. Fitzgibbons, A.R. Shah, and T.S. Park. 1994. Neuroprotection from ischemic brain injury by hypoxic preconditioning in the neonatal rat. Neurosci. Lett. 168:221-224.

33. Gavrieli, Y., Y. Sherman, and S.A. Ben-Sasson. 1992. Identification of programmed cell death in situ via specific labeling of nuclear DNA fragmentation. J. Cell Biol. 119:493-501.

34. Golden, J.P., J.Z. Rana, J. Davis, D.S. Zahm, and M.F. Jacquin. 1993. Organization of the proximal, orbital segment of the infraorbital nerve at multiple intervals after axotomy at birth: a quantitative electron microscopic study in rat. J. Comp. Neurol. 338:159-174.

35. Mobley, W.C., J.L. Rutkowski, G.I. Tennekoon, J. Gemski, K. Buchanan, and M.V. Johnston. 1986. Nerve growth factor increases choline acetyltransferase activity in developing basal forebrain neurons. Mol. Brain Res. 387: $53-62$

36. Holtzman, D.M., R.A. Sheldon, W. Jaffe, Y. Cheng, and D.F. Ferriero. 1996. NGF protects the neonatal brain against hypoxic-ischemic injury. Ann. Neurol. 39:114-122.

37. Paxinos, G., and C. Watson. 1986. The Rat Brain in Stereotaxic Coordinates. Academic Press, Australia. 237 pp.

38. Holtzman, D.M., R.M. Bayney, Y. Li, H. Khosrovi, C.N. Berger, C.J. Epstein, and W.C. Mobley. 1992. Dysregulation of gene expression in mouse trisomy 16, an animal model of Down syndrome. EMBO (Eur. Mol. Biol. Or gan.) J. 11:619-627.

39. Armstrong, R.C., T. Aja, K.D. Hoang, S. Gaur, X. Bai, E.S. Alnemri, G. Litwack, D.S. Karanewsky, L.C. Fritz, and K.J. Tomaselli. 1997. Activation of the CED3/ICE-related protease CPP32 in cerebellar granule neurons undergoing apoptosis but not necrosis. J. Neurosci. 17:553-562.

40. Ferriero, D.M., D.M. Holtzman, S.M. Black, and R.A. Sheldon. 1996 Mice without neuronal nitric oxide synthase have less injury after perinatal hypoxia-ischemia. Neurobiol. Dis. 3:64-71.

41. Wijsman, J.H., R.R. Jonker, R. Keijzer, C.J. van de Velde, C.J. Cornelisse, and J.H. van Dierendonck. 1993. A new method to detect apoptosis in paraffin sections: in situ end-labeling of fragmented DNA. J. Histochem. Cy tochem. 41:7-12.

42. Collins, R.J., B.V. Harmon, G.C. Gobe, and J.F.R. Kerr. 1992. Internucleosomal DNA cleavage should not be the sole criterion for identifying apoptosis. Int. J. Radiat. Biol. 61:451-453.

43. Ellis, R.E., J. Yuan, and H.R. Horvitz. 1991. Mechanisms and functions of cell death. Annu. Rev. Cell Biol. 7:663-698.

44. Ni, B., X. Wu, Y. Du, Y. Su, E. Hamilton-Byrd, P.K. Rockey, P.J. Rosteck, G.G. Poirer, and S.M. Paul. 1997. Cloning and expression of a rat brain interleukin-1beta-converting enzyme (ICE)-related protein (IRP) and its possible role in apoptosis of cultured cerebellar granule neurons. J. Neurosci. 17: 1561-1569.

45. Loddick, S.A., A. MacKenzie, and N.J. Rothwell. 1996. An ICE inhibitor, z-VAD-DCB attenuates ischaemic brain damage in the rat. Neuroreport. 7: $1465-1468$.

46. Hara, H., R.M. Friedlander, V. Gagliardini, C. Ayata, K. Fink, Z. Huang, M. Shimizu-Sasamata, J. Yuan, and M. Moskowitz. 1997. Inhibition of interleukin $1 \beta$ converting enzyme family proteases reduces ischemic and excitotoxic neuronal damage. Proc. Natl. Acad. Sci. USA. 94:2007-2012.

47. Hagan, P., J.D. Barks, M. Yabut, B.L. Davidson, B. Roessler, and F.S Silverstein. 1996. Adenovirus-mediated over-expression of interleukin-1 receptor antagonist reduces susceptibility to excitotoxic brain injury in perinatal rats. Neurosciences. 75:1033-1045.

48. Silverstein, F.S., J.D. Barks, P. Hagan, X.H. Liu, J. Ivacko, and J. Szaflarski. 1997. Cytokines and perinatal brain injury. Neurochem. Int. 30:375-383. 